DOI: 10.20472/IAC.2017.029.030

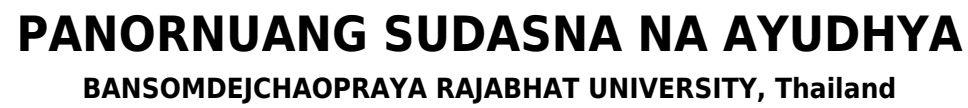

\title{
CROSS-LINGUISTIC SEMANTIC PRIMING OF TRANSLATION EQUIVALENTS IN SEMANTIC DECISION OF THAI-LAO-ENGLISH OBJECT AND IMAGINARY WORDS
}

\begin{abstract}
:
Eight semantic priming of translation equivalents in semantic decision of physical and imaginary words examined the influences of semantic priming effect obtained from translation equivalents towards the lexical access of object and imaginary words. Also, the degrees of translation equivalent differences were also represented by using primes and targets, which are from the same or different language families as Thai and English (Experiment $1-4$ ) or Thai and Lao (Experiment 5-8). With this aim, lexical decision experiments using semantic related in the experimental condition or unrelated in the control condition between primes and targets were conducted in both Thai-English and Thai-Lao prime-target languages. In each experiment, the words meaning object and imaginary were tested. The results revealed the effect of semantic priming effect obtained from translation equivalents, the effect of object and imaginary, and the effect of language of prime and target. The results were implied to the issues of second language acquisition, second language development, and second language lexicon.
\end{abstract}

\section{Keywords:}

semantic priming, translation equivalents, semantic decision

JEL Classification: C99 


\section{Introduction}

Presently, it is realized that the present world is multilingual and is becoming globalized. Language becomes an important communicative tool in human activities such as giving information, learning and teaching knowledge, or constructing social communication. In addition, most of people currently learn second or foreign language because knowing more than one language is useful for career path and progress, gaining awareness of other cultures and increasing understanding and knowledge towards language. Thus, it is common situation to learn at least 2 languages.

This research is interested to investigate the semantic effect obtained from translation equivalents in lexical access comparing between the effects obtained from translation equivalents found in two languages from the same language family and the effects obtained from translation equivalents found in two languages from the different language families.

According to the increase of studying translation equivalence (Kenny, 1998), American linguist Roman Jacobson (1959-2000: 114), who is one of the pioneers who proposed the concept of translation equivalence in meaning. Jacobson (1959) proposed that there is no exact translation equivalence between words of two languages. Jacobson proposed the example of the English word "cheese", which does not exactly have the translation equivalent of the Russian term. This is because Russian language does not have the word meaning "cottage cheese".

The translation equivalence continues to be an important point of study and discussion. Many theorists attempt to define, to characterize, and to explain the concept of translation equivalence between languages and getting translation equivalent words between languages (Fawcett, 1997) such as Catford (1965), Nida and Taber (1969), Newmark (1988), Vinay and Darbelnet (1958/1989), Baker (1992), and House (2002), the translation equivalence notion is defined, and explained depending on different views of each translation scholars. For the present study, the concept of interlingual (between two languages) translation equivalent by Jakobson (1959:232) was applied in this research.

Jakobson (1959:232) categorized three kinds of translation as intralingual (within one language), interlingual (between two languages), and intersemiotic (between sign systems). Regarding to the notion of interlingual translation, Jakobson claimed that the synonyms in the other language was used in order to get the ST message across. According to his explanation, 'translation involves two equivalent messages in two different codes' (ibid.233). Jakobson proposed that each languages differs from one another in different degrees, this may cause the problem of finding a translation equivalents between two languages. A number of examples revealed that when there is no a literal equivalent for a particular source language and the translator must select the most appropriated word to transmit the meaning in the target language. 
According to Jakobson (1959), in the present investigation, it is hypothesize those different degrees of translation equivalents among languages will influence to the priming effect towards lexical access. Thus, this hypothesis was examined by comparing lexical access between two source and target language pairs. The first source and target language pair were Thai and English, which are from different language family. The second source and target language pair were Thai and Lao, which are from same language family. The translation equivalents were investigated and prepared from the study of Thai-ASEAN Neighboring Language - English Common Base Concepts WordNet of $1^{\text {st }}$ Order Entity by (Sudasna Na Ayudhya, 2015). The effect was investigating by using semantic priming task and lexical decision respond.

According to Horner and Henson (2008), priming task consists of a previously presented stimulus or the "prime", which facilitates or inhibits a response towards the next presented stimulus or the "target". Priming tasks are used to examine a linguistic performance which can be predicated according to a particular type of relation between a prime and a target such as orthographic, phonetics, or semantic relations (Cattel 1888/1947; Harley, 2005). Priming effect is occurred from facilitation of word recognition or lexical access by prior exposure to a prime, which is related or unrelated in linguistic characteristics as orthographic, phonetics, or meaning (Stremme and Johansson, 2015). Priming effect can influence retrieving words in two different ways. If a prime makes target recognition faster, it is called facilitation. Whereas, if a prime makes a target recognition slower. It is called inhibition. Whether the priming effect will be facilitation or inhibition, it depends on the relation between primes and targets. (Keatley, Spinks, and De Gelder (1994).

One of the most common types of priming is semantic priming (Chen and $\mathrm{Ng}, 1989$ ). Semantic priming is produced by the relation of meaning between prime and target. This kind of priming was begun by Meyer and Schvaneveldt (1971)'s research. According to Meyer and Schvaneveldt (1971)'s research, subjects were asked to make decision whether two simultaneously presented letter strings were words or not words such as a word pair of "table-grass" is word or not word. In this experiment, half of the word pairs have semantic relation such as a word pair of "table-chair" and another half was not such as a word pair of "bread-grass". The results revealed that participants provided faster responses when word pairs were semantically related compared to when word pairs were not related. This effect is called "semantic priming" (McNamara, 2005).

Priming effect including semantic priming effect can be measured by different methods. Using semantic decision task is one of important and usual method to measure priming effect. In a semantic decision task, a subject is asked to make semantic judgment of a target word. In a semantic decision task, subjects are asked to indicate the semantic category of the target (Bueno, \& Frenck-Mestre, 2008). It is hypothesized that subjects will respond to the tasks faster if the target is preceded by another prime related in meaning. 
The aim of the present work was to investigate the influences of semantic priming effect obtained from translation equivalents towards the lexical access of object and imaginary words. Also, the degrees of translation equivalent differences were also represented by using primes and targets, which are from the same or different language families as Thai and English (Experiment 1 -4) or Thai and Lao (Experiment 5-8). The experimental words were selected from the study of Thai-ASEAN Neighboring Language - English Common Base Concepts WordNet of $1^{\text {st }}$ Order Entity by Sudasna Na Ayudhya (2015) and the control procedures which are usual in semantic priming experiments was adopted.

\section{Experiment 1 and 4}

\section{Method}

Subjects. Fifty $1^{\text {st }}$ year Thai undergraduate students, who studied English as foreign language (42 women, 8 men) from Bansomdejchaopraya Rajabhat University (Bangkok, Thailand), with ages ranging from 18 to 20 were selected as the subjects. They received a course credit for their participation.

\section{Materials and design}

The experimental condition consisted of two experiments: Experiment 1 and 2. In Experiment 1,80 Thai and English translation equivalent pairs referring to objects were selected from the study of Thai-ASEAN Neighboring Language - English Common Base Concepts WordNet of $1^{\text {st }}$ Order Entity by Sudasna Na Ayudhya (2015). These 80 Thai and English translation equivalent pairs were divided as two sets. The first set was composed by 40 Thai words used as targets and English translation equivalence used as primes. The second set was composed by 40 English words used as targets and Thai translation equivalence used as primes.

In Experiment 2, 80 Thai and English translation equivalent pairs referring to imaginary were selected from the study of Sudasna Na Ayudhya (2015). These 80 Thai and English translation equivalent pairs were divided as two sets. The first set was composed by 40 Thai words used as targets and English translation equivalence used as primes. The second set was composed by 40 English words used as targets and Thai translation equivalence used as primes.

The control condition consisted of two experiments: Experiment 3 and 4 . In Experiment 3, 40 Thai words used as targets in Experiment 1 and 40 Thai words used as targets in Experiment 2 were used as targets and English unrelated words used as primes. In Experiment 4, 40 English words used as targets in Experiment 1 and 40 Thai words used as targets in Experiment 2 were used as targets and Thai unrelated words used as primes. 
The research design of Experiments 1-4 was presented in Table 1 and the examples of experimental pairs were presented in Table 2

Table 1: Research design of Experiments 1-4

\begin{tabular}{ccccc}
\hline & \multicolumn{2}{c}{ Prime: English (L2 ${ }^{1}$ ) } & $\begin{array}{c}\text { Prime: Thai (L1) } \\
\text { Target: English (L2) }\end{array}$ \\
\hline & Target: Thai (L1 ${ }^{2}$ ) & & \\
\hline & Control & Experimental & Control & Experimental \\
(Unrelated) & (Translation & (Unrelated) & (Translation \\
& & Equivalence) & & Equivalence) \\
Objects & Experiment & Experiment & Experiment 4 & Experiment \\
& 3 & $1 /$ Set 1 & & $1 /$ Set 2 \\
Imaginary & Experiment & Experiment & Experiment 4 & Experiment \\
& 3 & $2 /$ Set 1 & & $2 /$ Set 1 \\
\hline
\end{tabular}

Table 2: Examples of experimental pairs

\begin{tabular}{ccccc}
\hline & \multicolumn{2}{c}{$\begin{array}{c}\text { Prime: English (L2) Target: } \\
\text { Thai (L1) }\end{array}$} & \multicolumn{2}{c}{ Prime: Thai (L1) } \\
Target: English (L2)
\end{tabular}

Words used as primes and targets in both control and experimental condition were matched for word frequency and length.

By crossing the two variables above described, forty groups of four experimental pairs were obtained as presented in Table 2 for examples. Four different versions of experiments were constructed. So that there were 160 primes- target pairs appeared under the four priming conditions across participants, but any participant did not see any prime or target more than once.

A practice block of eight pairs was constructed. This block included examples of each type of prime-target pair in the same proportion as the experimental set.

\footnotetext{
${ }^{1} \mathrm{~L} 2$ is the abbreviation of second language.

${ }^{2} \mathrm{~L} 1$ is the abbreviation of first language.
} 


\section{Procedure and apparatus.}

The subjects were tested by the experiments individually in separate computer desktop. The four experimental lists were assigned to individual subjects randomly. The subjects were given written instructions about the task before they performed the task. Each experimental trial consisted of a black dot fixation point appeared in the center of the computer screen for $500 \mathrm{~ms}$. Then it was replaced by the prime presented for $150 \mathrm{~ms}$. and the prime was immediately substituted by the target displayed for $1000 \mathrm{~ms}$.

The subjects were asked to indicate whether the target meaning was object or imaginary, by pressing right or left shift buttons. Half of the subjects were asked to press right shift button for the "objects" and left shift button for the "imaginary". The other half of the subjects were asked to press right shift button for the "imaginary" and left shift button for the "object" The order of prime-target pair presentation was randomized for each individual.

The stimulus items were displayed and the reaction times and error percentages were recorded by the DMDX package developed by Forster and Forster (2003).

\section{Results}

Incorrect responses were excluded from the analyses. Reaction times (RTs, in milliseconds) were more than two standard deviations above and below the individual subject's mean in all conditions were set up as the appropriate cutoff values to moderate the influence of outliers. As a result, $2.7 \%$ of the data were excluded.

Two way ANOVAS were carried out to analyze RTs and error data both by subjects and by items. The analysis of subjects' means of reaction times (RT) and the percentage of errors are presented in Table 3.

Table 3: Results (mean and standard error of the mean in parentheses)

\begin{tabular}{ccccccccc}
\hline & \multicolumn{3}{c}{$\begin{array}{c}\text { Prime: English (L2) Target: } \\
\text { Thai (L1) }\end{array}$} & \multicolumn{3}{c}{$\begin{array}{c}\text { Prime: Thai (L1) } \\
\text { Target: English (L2) }\end{array}$} \\
\hline \multirow{6}{*}{ Objects } & $\begin{array}{c}\text { Control } \\
\text { (Unrelated) }\end{array}$ & $\begin{array}{c}\text { Experimental } \\
\text { (Translation } \\
\text { Equivalence) }\end{array}$ & $\begin{array}{c}\text { Control } \\
\text { (Unrelated) }\end{array}$ & $\begin{array}{c}\text { Experimental } \\
\text { (Translation }\end{array}$ \\
& RT & error & RT & error & RT & error & RT & error \\
& 598 & 12.1 & 571 & 8.4 & 581 & 10.6 & 569 & 7.9 \\
Imaginary & $(11.2)$ & $(0.9)$ & $(10.1)$ & $(0.7)$ & $(10.4)$ & $(0.9)$ & $(10.0)$ & $(0.7)$ \\
& 604 & 14.2 & 584 & 12.6 & 592 & 11.3 & 573 & 8.7 \\
& $(12.4)$ & $(0.9)$ & $(11.3)$ & $(0.8)$ & $(11.1)$ & $(0.9)$ & $(10.2)$ & $(0.8)$ \\
\hline
\end{tabular}


A main effect of translation equivalent was revealed by the analysis of RTs that was significant both by participants, $\mathrm{F} 1(1,50)=6.71, \mathrm{p}<.05, \eta 2 \mathrm{p}=0.261$, and by items, $F 2(1,79)=7.46, p<.05, \eta 2 p=0.285$.

The effect of object and imaginary words was revealed by the analysis of RTs that was significant both by participants, $F 1(1,50)=9.11, p<.05, \eta 2 p=0.355$, and by items, $F 2(1,79)=10.28, p<.05, \eta 2 p=0.371$.

The effect of language of prime and target (L2 as Prime-L1 as Target; L1 as Prime-L2 as Target) was revealed by the analysis of RTs that was significant both by

participants, $F 1(1,50)=11.08, p<.05, \eta 2 p=0.736$, and by items, $F 2(1,79)=14.51, p<.05$, $\eta 2 p=0.844$.

The results of the present experiment illustrated that there was a semantic priming effect caused from translation equivalent prime. That is subjects responded faster to primes and targets, which were translation equivalent related than to primes and targets, which were unrelated. In addition, there is the significant effect caused from whether L1 or L2 is used as prime or target language.

\section{Experiment 5 and 8}

\section{Methodology}

Subjects. Fifty $1^{\text {st }}$ year Thai undergraduate students, who studied Vietnamese as foreign language (37 women, 13 men) from Bansomdejchaopraya Rajabhat University (Bangkok, Thailand), with ages ranging from 18 to 20 were selected as the subjects. They received a course credit for their participation.

\section{Materials and design.}

The experimental condition consisted of two experiments: Experiment 5 and 6 . The Experiment 5, 80 Thai and Lao translation equivalent pairs referring to objects were selected from the study of Sudasna Na Ayudhya (2015). The experimental conditions were the same as in Experiment 1.

The Experiment 6, 80 Thai and Lao translation equivalent pairs referring to imaginary were selected from the study of Sudasna Na Ayudhya (2015). The experimental conditions were the same as in Experiment 2.

The control condition consisted of two experiments: Experiment 7 and 8 conditions were the same as in Experiment 3 and 4.

The research design of Experiments 5-8 was presented in Table 4 and the examples of experimental pairs were presented in Table 5. 
Table 4: Research design of Experiments 5-8

\begin{tabular}{ccccc}
\hline & \multicolumn{2}{c}{ Prime: Lao (L2) } & \multicolumn{2}{c}{ Prime: Thai (L1) } \\
& Target: Thai (L1) & \multicolumn{2}{c}{ Target: Lao (L2) } \\
\hline & Control & Experimental & Control & Experimental \\
& (Unrelated) & (Translation & (Unrelated) & (Translation \\
& & Equivalence) & & Equivalence) \\
Objects & Experiment & Experiment & Experiment 4 & Experiment \\
& 3 & $1 /$ Set 1 & & $1 /$ Set 2 \\
Imaginary & Experiment & Experiment & Experiment 4 & Experiment \\
& 3 & $2 /$ Set 1 & & 2/Set 1 \\
\hline
\end{tabular}

Table 5: Examples of experimental pairs

\begin{tabular}{|c|c|c|c|c|}
\hline & \multicolumn{2}{|c|}{$\begin{array}{l}\text { Prime: Lao (L2) } \\
\text { Target: Thai (L1) }\end{array}$} & \multicolumn{2}{|c|}{$\begin{array}{l}\text { Prime: Thai (L1) } \\
\text { Target: Lao (L2) }\end{array}$} \\
\hline & $\begin{array}{c}\text { Control } \\
\text { (Unrelated) }\end{array}$ & $\begin{array}{l}\text { Experimental } \\
\text { (Translation } \\
\text { Equivalence) }\end{array}$ & $\begin{array}{c}\text { Control } \\
\text { (Unrelated) }\end{array}$ & $\begin{array}{l}\text { Experimental } \\
\text { (Translation } \\
\text { Equivalence) }\end{array}$ \\
\hline Objects & บึถา-ดิน & ถึบ-ดิน & ควาย-ชัมๆ & หมา-ชัมๆ \\
\hline Imaginary & $\begin{array}{l}\text { వะขอับ - } \\
\text { ความรัก }\end{array}$ & ธัภ -ความรัก & นรก-ถอามธู้ & ความรู้-ถอามธู้ \\
\hline
\end{tabular}

\section{Procedure and apparatus}

The procedure was exactly the same as in Experiment 1 - 4.

\section{Results}

Incorrect responses were excluded from the analyses. Reaction times (RTs) were more than two standard deviations above and below the individual subject's mean in all conditions were set up as the appropriate cutoff values to moderate the influence of outliers. As a result, $0.9 \%$ of the data were excluded.

One way ANOVAS were carried out to analyze RTs and error data both by subjects and by items. The analysis of subjects' means of reaction times and the percentage of errors are presented in Table 3. 
Table 6: Results (mean and standard error of the mean in parentheses)

\begin{tabular}{|c|c|c|c|c|c|c|c|c|}
\hline & \multicolumn{4}{|c|}{$\begin{array}{c}\text { Prime: Lao (L2) Target: Thai } \\
\text { (L1) }\end{array}$} & \multicolumn{4}{|c|}{$\begin{array}{l}\text { Prime: Thai (L1) } \\
\text { Target: Lao (L2) }\end{array}$} \\
\hline & \multicolumn{2}{|c|}{$\begin{array}{c}\text { Control } \\
\text { (Unrelated) }\end{array}$} & \multicolumn{2}{|c|}{$\begin{array}{l}\text { Experimental } \\
\text { (Translation } \\
\text { Equivalence) }\end{array}$} & \multicolumn{2}{|c|}{$\begin{array}{c}\text { Control } \\
\text { (Unrelated) }\end{array}$} & \multicolumn{2}{|c|}{$\begin{array}{l}\text { Experimental } \\
\text { (Translation } \\
\text { Equivalence) }\end{array}$} \\
\hline & $\mathrm{RT}$ & error & $\mathrm{RT}$ & error & $\mathrm{RT}$ & error & RT & error \\
\hline Objects & $\begin{array}{c}581 \\
(10.2)\end{array}$ & $\begin{array}{c}6.4 \\
(0.7)\end{array}$ & $538(6.2)$ & $\begin{array}{c}1.4 \\
(0.4)\end{array}$ & $\begin{array}{c}579 \\
(10.1)\end{array}$ & $\begin{array}{c}6.8 \\
(0.7)\end{array}$ & $\begin{array}{l}533 \\
(6.0)\end{array}$ & $\begin{array}{c}0.9 \\
(0.3)\end{array}$ \\
\hline Imaginary & $\begin{array}{r}586 \\
(11.3) \\
\end{array}$ & $\begin{array}{r}7.6 \\
(0.8) \\
\end{array}$ & $\begin{array}{l}547 \\
(7.6) \\
\end{array}$ & $\begin{array}{r}3.5 \\
(0.5) \\
\end{array}$ & $\begin{array}{r}584 \\
(10.8) \\
\end{array}$ & $\begin{array}{r}7.3 \\
(0.7) \\
\end{array}$ & $\begin{array}{l}541 \\
(7.2) \\
\end{array}$ & $\begin{array}{r}3.0 \\
(0.5) \\
\end{array}$ \\
\hline
\end{tabular}

A main effect of translation equivalent was revealed by the analysis of RTs that was significant both by participants, $\mathrm{F} 1(1,50)=12.03, \mathrm{p}<.05, \eta 2 \mathrm{p}=0.537$, and by items, $\mathrm{F} 2(1,79)=7.46, \mathrm{p}<.05, \eta 2 \mathrm{p}=0.644$.

The effect of object and imaginary words was revealed by the analysis of RTs that was significant both by participants, $F 1(1,50)=9.11, p<.05, \eta 2 p=0.271$, and by items, $F 2(1,79)=9.43, p<.05, \eta 2 p=0.298$.

The effect of language of prime and target (L2 as Prime-L1 as Target; L1 as Prime-L2 as Target) was revealed by the analysis of RTs that was not significant both by

participants, $F 1(1,50)=2.11, p .=.34$ and by items, $F 2(1,79)=2.72, p=.44$.

The results of the present experiment illustrated that there was a semantic priming effect. That is subjects responded faster to primes and targets, which were translation equivalent related than to primes and targets, which were unrelated. Whereas, there is no significance caused from whether L1 or L2 is used as prime or target language. This implied that there is no significant difference between the conditions whetherThai or Lao is used as prime or target language.

\section{Conclusion}

In the present study, the influence of translation equivalents on semantic priming effect was test in the lexical decision of object and imaginary words. In addition, this influence was investigated in order to consider whether the degrees of differences between the language used as prime and target would obtain the different degree of semantic priming effect. In this study, the degrees of differences between the language used as prime and target were represented by selecting language used as prime and target from the same or different language families. That is, Thai and English are from different language families and are used as primes and targets in Experiment $1-4$ and Thai and Lao are from same language family and are used as 
primes and targets in (Experiment 5-8). The present study, the recognition was divided between object and imaginary word recognition.

The results of the study revealed that there is the semantic priming effect obtained from translation equivalents in both object and imaginary word retrieval. However, the obtained semantic priming effect obtained from two types of prime and target language differences: prime and target languages are from the same language family and are form the different language families. The result presented in the condition of prime and target languages from the same language family, there is no significant difference whether prime and target languages were L1 or L2. Whereas, the condition of prime and target languages from the different language families showed significant difference when prime and target languages were L1 or L2. This can be implied that there is no significant difference when Thai and Lao were used as prime and target and vice versa. This can be explained by the relation between Thai and Lao languages, which belong to the Tai language family and are closely related. Especially, it was investigated from the previous linguistic studies ( Diller, Edmondson, and Luo, 2004; Mollerup, 2001) that most of the words in Thai and Lao are similar in meaning; eventually some words have the same meaning but are used in different contexts in the two languages such as the word for "house" in Lao also meaning "house" in Thai but these two words are used differently in formality level between two languages. The results of the present study can be further implied to the issues of second language acquisition, second language development, and second language lexicon.

\section{References}

BAKER, M. (1992) In Other Words: A Coursebook on Translation. London: Routledge.

BUENO, S. and FRENCK-MESTRE, C. (2008). The Activation of Semantic Memory: Effects of Prime Exposure, Prime-Target Relationship, and Task Demands. Memory \& Cognition. 2008, Vol. 36, pp. 882-898.

CATFORD, J. C. (1965) A Linguistic Theory of Translation: An Essay on Applied Linguistics. London: Oxford University Press.

CHEN, H.-C. and NG, M.-L. (1989). Semantic Facilitation and Translation Priming Effects in

Chinese-English Bilinguals. Memory \& Cognition. 1989, Vol. 17, No. 4, pp. 454-462.

DILLER, A; EDMONDSON, J; and LUO, Y. (2004) The Tai-Kadai Languages. New York: Routledge, pp. 5-6.

FAWCETT, P. (1997) Translation and Language: Linguistic Theories Explained. Manchester: St Jerome Publishing.

FORSTER, K. I. and FORSTER, J. C. (2003). DMDX: A Windows Display Program with Millisecond Accuracy. Behavior Research Methods, Instruments, \& Computers. Vol. 35,pp. 116-124.

HORNER, A. and HENSON, R. J. (2008): Priming, Response Learning and Repetition Suppression. Neuropsychologia. 2008, Vol. 46, No.7, pp. 1-25. 
HOUSE, J. (1977) A Model for Translation Quality Assessment. Tübingen: Gunter Narr.

JAKOBSON, R. (1959) On Linguistic Aspects of Translation, in R. A. Brower (ed.) On Translation. Cambridge. MA: Harvard University Press, pp. 232-39.

KEATLEY, C. W.; SPINKS, J. A. and DE GELDER, B. (1994). Asymmetrical Cross-Language Priming Effects. Memory \& Cognition. 1994, Vol. 22, No. 1, pp. 70-84.

KENNY, D. (1998) Equivalence, in Mona Baker (ed.) the Routledge Encyclopaedia of Translation Studies. London and New York: Routledge, pp.77-80.

MEYER, D. E. and SCHVANEVELDT, R. W. (1971). Facilitation in Recognizing Pairs of Words:

Evidence of a Dependence between Retrieval Operations. Journal of Experimental Psychology. 1971, Vol.90, pp.227-234.

McNAMARA, T.P. (2005). Semantic Priming: Perspectives from Memory and Word

Recognition. New York: Psychology Press.

MOLLERUP, A. (2001) Thai-Isan-Lao Phrasebook. Bangkok: White Lotus.

NIDA, E. A. (1964) Towards a Science of Translating. Leiden: E. J. Brill.

NIDA, E. A. and TABER, C.R. (1969 / 1982) The Theory and Practice of Translation. Leiden: E. J. Brill.

STREMME, C. and JOHANSSON, C. (2015). Beyond Reaction Time: Priming across Languages.Talk at PIF 2015 conference. , May 21-23, 2015.

SUDASNA NA AYUDHYA, P. (2015). The Development of Application for Thai-ASEAN Neighboring Language English Common Base Concepts WordNet of $1^{\text {st }}$ Order Entity. Research Report. (Unpublished).

VINAY, J.P. and DARBELNET, J. (1995) Comparative Stylistics of French and English: A Methodology for Translation, translated by J. C. Sager and M. J. Hamel, Amsterdam / Philadelphia: John Benjamins. 